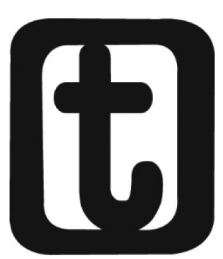

\title{
SERVIÇO SOCIAL, NEOCONSERVADORISMO RELIGIOSO E O DESAFIO PARA A FORMAÇÃO PROFISSIONAL
}

\author{
SOCIAL WORK, RELIGIOUS NEOCONSERVATISM AND \\ THE CHALLENGE FOR VOCATIONAL TRAINING
}

Paulo Wescley Maia Pinheiro'

\section{RESUMO}

O presente artigo é fruto da dissertação de mestrado intitulada, "Serviço Social e neoconservadorismo religioso: a percepção dos/as estudantes e os desafios para o projeto ético-político", que objetivou analisar a incidência do discurso neoconservador religioso no espaço de formação profissional, com base na fala das/dos estudantes e percepções quanto aos aspectos ético-políticos do Serviço Social. Para tal, realizamos pesquisa bibliográfica sobre as categorias trabalho e reprodução social, neoconservadorismo religioso e formação profissional em Serviço Social; e pesquisa de campo com estudantes de graduação do curso de Serviço Social da Universidade Estadual do Ceará. Para esse artigo, apresentamos parte das análises dos dados colhidos em campo sobre a imagem da profissão. A partir da referida investigação, verificamos que há um forte caráter conservador, abalizado pelo fundamentalismo religioso em amplos setores da sociedade, que se espraia por todas as dimensões da vida, contexto em que a profissão e a formação em Serviço Social também estão inseridas.

Palavras-chave: Serviço social; Neoconservadorismo religioso; Formação profissional.

1 Professor do Departamento de Serviço Social da Universidade Federal de Mato Grosso. Assistente social e Mestre em Serviço Social, trabalho e questão social pela Universidade Estadual do Ceará (UECE). Vice-presidente da Associação Brasileira de Ensino e Pesquisa em Serviço Social - Centro-oeste. 


\section{temporalis}

\section{ABSTRACT}

This article is the result of the dissertation entitled, "Social Work and religious neoconservatism: the perception of / the students and the challenges to the ethical-political project", which aimed to analyze the impact of religious neoconservative discourse in the professional training area, from the speech / students and perceptions of the ethical and political aspects of social work. To this end, we conducted literature on the categories work and social reproduction, religious neoconservatism and training in social work; and field research with / the graduate students of the social service program of the State University of Ceará. For this article, we present part of the analysis of data collected in the field on the image of the profession. From that research, we found that there is a strong conservative character, authoritative religious fundamentalism in broad sectors of society, which spreads all dimensions of life, the context in which the profession and training in social work are also included.

Keyword: Social work; Religious neoconservatism; Vocational training.

Submetido - 05/03/2015

Aceito - 19/05/2015

\section{INTRODUÇÃO}

O cenário contemporâneo revela forte crescimento das expressões públicas de posicionamentos conservadores em contraposição a históricas bandeiras de lutas dos direitos humanos, reverberando em organizações de diversos âmbitos, tendo grande evidência em grupos religiosos. Esse fenômeno torna-se cotidiano em muitos espaços e aparece inclusive em ambientes de formação da juventude.

O Serviço Social não está imune a esse processo, ainda que seu projeto profissional, desde os anos 1980, seja hegemonizado pelo campo crítico de horizonte emancipatório. Nesse sentido, observamos de modo muito frequente uma tensão entre o projeto historicamente defendido pela categoria, que postula, dentre outros elementos, a defesa dos direitos humanos, e o atual contexto neoconservador, que se expressa inclusive em grupos inseridos na juventude universitária.

Diante dessas constatações, a pesquisa que motivou esse texto objetivou ${ }^{2}$ analisar o avanço do pensamento neoconservador no

2 Destacamos que a pesquisa de dissertação intitulada "Serviço Social e neoconservadorismo religioso: a percepção dos/as estudantes e os desafios para o projeto ético-político" realizada para obtenção do título de mestre no Programa de Pós-graduação - mestrado acadêmico em Serviço Social, Trabalho e Questão Social, foi avaliada e aprovada pelo Comitê de Ética da Universidade Estadual do 
Serviço Social, enfocando a incidência do caráter fundamentalista religioso nas percepções ético-políticas e teórico-metodológicas dentro do espaço de formação profissional, com base nos posicionamentos das/dos estudantes de graduação. A pesquisa de campo aconteceu no curso de Serviço Social da Universidade Estadual do Ceará, no primeiro período letivo de 2013, junto aos (às) estudantes, prioritariamente do primeiro, quinto e sétimo semestres letivos, buscando visões e entendimentos em tempos distintos do processo de formação.

Nesse sentido, compreendemos o conservadorismo moderno ${ }^{3}$ de acordo com o complexo ideológico oriundo das determinações do amadurecimento da hegemonia burguesa, que consubstancia elementos dispares para a naturalização da essência do modo de vida calcado na exploração do trabalho e nas opressões historicamente determinadas. As manifestações contemporâneas de ordens diversas desse constructo incidem na sociedade e na profissão de Serviço Social com novas expressões e mediações, sob o aspecto tradicional metamorfoseado, consoante prismas diferentes, tendo incidência no modo atual de enfretamento das expressões da questão social pelo Estado neoliberal, além das manifestações no campo da moral e dos valores, como problematiza Barroco (2011).

Nesse amplo arco de elementos, percebemos que o neoconservadorismo religioso ${ }^{4}$ cumpre funções importantes para a reprodu-

Ceará (UECE).

3 As reflexões trazidas nesse texto são uma síntese que assevera o fenômeno do neoconservadorismo não como algo essencialmente novo, mas sim como um produto do constructo da reprodução social da sociedade de classes, que se manifesta sob níveis, formas e planos diferentes e incidem no cotidiano dos sujeitos nas disputas, manutenções e reproduções dos antagonismo basilares da sociabilidade burguesa (LUKÁCS, 2013). Para uma abordagem mais profunda da categoria conservadorismo ver Netto (2011) e lamamoto (1992) que destacam a importância da temática para a compreensão da gênese do o Serviço Social. Sobre o fenômeno do neoconservadorismo na profissão, Santos (2009) elenca elementos fundamentais do plano teórico abordando o tema da pós-modernidade e suas correntes.

4 Nesse último plano, compreender o protagonismo na cena pública dos posicionamentos religiosos, implica à reflexão sobre o complexo diálogo do exercício da dimensão da religiosidade individual com os preceitos dogmáticos das instituições religiosas, percebendo o caráter ontologicamente conservador da naturalizaçãoo das relações por meio de uma essência sobrenatural, como coloca Lukács (2010), compreendendo também o caráter contraditório e de expressões diversas no interior das crenças e de suas instituições, reflexos das disputas por hegemonia no caldo cultural das classes sociais, como destaca Lowi (2000), 


\section{temporalis}

ção cultural das desigualdades, desde o cotidiano dos sujeitos até as questões políticas de ataque e supressão de direitos. A lógica machista, patriarcal e heterossexista ganha fôlego nos dogmas e doutrinas em seus vieses fundamentalistas.

Nesse texto veremos que o ranço histórico de conservadorismo e a subalternidade atribuída ao longo do tempo à profissão reforçam um entendimento equivocado da imagem do Serviço Social para aqueles que adentram no curso sob a expectativa da caridade e do voluntarismo. Ficarão evidentes, também, alguns dos diversos embates subjetivos das estudantes ao se depararem com as contradições de seus valores e posicionamentos com temáticas que surgem no processo de formação profissional, sobretudo, ao abordar questões referentes à desnaturalização dos valores e assuntos ligados a diversidade sexual, direitos reprodutivos, entre outros.

\section{NEOCONSERVADORISMO RELIGIOSO, FORMAÇÃO PROFISSIONAL E O PROJETO ÉTICO-POLÍTICO DO SERVIÇO SOCIAL}

Entender a gênese do Serviço Social como práxis desenvolvida em um processo histórico para atender determinadas demandas, tendo em vista a maturidade da sociedade burguesa e suas contradições, é perceber a natureza conservadora em que se processou a consolidação profissional para a administração das expressões do conflito capital-trabalho.

A percepção crítica das últimas décadas, ao desvendar esse postulado, permite uma reflexão profunda dos limites e das possibilidades da esfera da atuação profissional. É nessa perspectiva que se expressa o avanço para a luta coletiva junto aos anseios da classe trabalhadora, na organização política da categoria e na construção teórica de seus agentes.

apreendendo, assim, a possibilidade de diferentes modos de encarar a esfera da religiosidade, tanto individualmente, como em frações das diferentes religiões. Nesse sentido, é preciso refletir sobre o fundamentalismo religioso como expressão particular que ganha corpo e capilaridade na atual conjuntura, para a propagação de um viés absoluto de determinadas crenças e evidencia o plano político como um espaço importante para a defesa intolerante ante aos conceitos e valores diferentes e divergentes, configurando-se como expressão funcional à manutenção de privilégios e da essência do binômio exploração/opressão em tempos de decadência ideológica e de crise estrutural do capital. 
A síntese atual, que nos permite desvendar as determinações do advento da profissão, nos lança distante da visão endógena, presente em parte significativa da remota literatura do Serviço Social, a qual analisava o desenvolvimento profissional como um avanço gradual e natural das práticas filantrópicas.

O debate centrado na questão dos preconceitos aparece justamente a partir da aproximação, aprofundamento e consolidação da teoria crítica marxiana e marxista na formação, pesquisa e atuação profissional. O Serviço Social passa a pensar o mundo, suas relações, seus fundamentos de maneira distinta à de outrora. Nesse processo, repensa também o entendimento sobre a natureza da profissão, seus objetivos, seu objeto de intervenção, as dimensões políticas de sua atuação e de sua organização coletiva, além dos aspectos interventivos e operativos no limiar do cotidiano profissional, buscando a desnaturalização das mais diversas desigualdades.

Por isso, é imperativo entender o longo e complexo lastro de afirmação, reforço e busca de superação do conservadorismo na categoria, desde os limites de suas primeiras formas como profissão, nos aspectos ligados à ação católica e seu peculiar romantismo e moralismo conservador das contradições sociais, no qual os preconceitos estavam imersos na naturalização das opressões e desigualdades.

O fenômeno da hegemonia conservadora na profissão perdurou ainda, nas primeiras fases do chamado "movimento de renovação" nos anos 1960-1970 (NETTO, 2011b). Com a consolidação acadêmica da fase chamada de "intenção de ruptura", em meados dos anos 1980, temos a possibilidade de estudos e pesquisas aprofundando-se na tradição marxista, desenvolvendo-se num diálogo não homogêneo da categoria e da construção teórica na profissão, mas elaborando uma hegemonia numa perspectiva pluralista. Em 1982, Marilda lamamoto publica seu trabalho, Legitimidade e crise do Serviço Social, em que busca compreender e repensar a profissão fundamentando-se nas obras de Marx, como os Grundrisse e O Capital5.

5 É preciso destacar o já conhecido debate sobre o "marxismo sem Marx" no início dessa fase e todos os seus limites e contradições. Nesse caso particular, Netto (2011b, p. 294) reconhece a contribuição, mas faz ressalvas sobre sua discussão em relação a divisão social do trabalho e as novas segmentações do trabalho no capitalismo. Para o autor seu aprofundamento na tradição marxiana trouxe bases para compreender a profissão, contudo "[...] faltou o suporte de análises mais modernas, a partir do exame do movimento mais recente da ordem burguesa". 


\section{temporalis}

Esse aprofundamento do Serviço Social nos referenciais marxistas e marxianos nos anos 1980, avançou na década de 1990 e fundamentou a nova direção teórico-metodológica, ético-política e técnico-operativa da profissão. A tradição marxista vai ser referência básica e, depois, hegemônica no Serviço Social, direcionando-se para o rompimento com o conservadorismo. A expansão da pós-graduação, mestrado e doutorado, na área do Serviço Social, foi um espaço primordial para o aprofundamento teórico-metodológico da profissão.

O Serviço Social passou a pesquisar, analisar e produzir conhecimento sobre a natureza, os procedimentos, a formação e a história da profissão, bem como em relação à realidade social, política, econômica e cultural do Brasil e sobre os movimentos sociais, direitos sociais, democracia, cidadania, repensando as políticas sociais e outros espaços sócio-ocupacionais da profissão.

É por isso que, para suprir essas questões, se propôs definitivamente colocar a dimensão ética como uma discussão crucial para a categoria dos assistentes sociais, pois as diretrizes tiradas dessa síntese dos debates e a forma como se entende a ética e os valores que a profissão pretende cultivar e defender em sua atuação profissional são elementos fundamentais para uma identidade legítima, um discurso coeso e posicionamentos claros frente aos dilemas profissionais e polêmicas oriundas das particularidades do campo de atuação e de toda a sociedade (NETTO, 2006).

Em contrapartida a esse processo, as transformações ocorridas em 1990 no Brasil, especialmente a adoção do modelo capitalista neoliberal, trouxeram alterações substantivas para a realidade social, como os processos de privatizações e desmontes de direitos conquistados, aprofundando a pobreza e a miséria e outras tantas expressões da questão social.

É nesse contexto de escolhas teóricas e políticas realizadas pela profissão, mediante o fortalecimento da intenção de ruptura, precisamente na segunda metade dos anos 1990, em que se dá o debate aprofundado e a legitimação do que hoje chamamos de projeto ético-político, ainda que em condições inegavelmente mais adversas nos aspectos estruturais e conjunturais.

Mesmo com algumas ressalvas, o autor deixa claro que a produção de lamamoto consolida a vertente de intenção de ruptura no plano teórico-crítico, embasado na teoria marxiana e marxista. 


\section{tempordils}

Braz e Teixeira (2006) afirmam que esse projeto é fundamentado por: princípios e valores éticos; matriz teórico-metodológica em que se ancora; crítica radical à sociedade do capital; lutas e posicionamentos políticos acumulados pela categoria das/dos assistentes sociais em suas organizações políticas e em sua articulação com outros movimentos sociais.

O projeto ético-político está expresso, se desenvolve e busca sua materialização na atuação profissional por meio de alguns elementos, a saber: da produção de conhecimento no interior do Serviço Social, em que se reflete sobre o fazer profissional e a realidade contemporânea, negando teorias que reforcem o conservadorismo de outrora; das instâncias político-organizativas da profissão, como fóruns de deliberação, entidades, Conselho Federal de Serviço Social (CFESS), Conselhos Regionais de Serviço Social (CRESS), Associação Brasileira de Ensino e Pesquisa em Serviço Social (ABEPSS), centros e diretórios acadêmicos das unidades de ensino, Executiva Nacional de Estudantes de Serviço Social (ENESSO), espaços onde se afirmam os compromissos e os princípios da profissão, requerendo ambientes democráticos de construção coletiva, que, como atentam Braz e Teixeira (2006), estão em permanente disputa pela hegemonia; e da dimensão jurídico-política da profissão, por meio do Código de Ética e Lei que Regulamenta a Profissão de 1993 e das novas Diretrizes Curriculares aprovadas em 1996.

A legitimação do PEP não elimina as tensões, divergências e contradições, sempre haverá o confronto de ideais, parte da categoria propondo projetos divergentes, fundamentado em outra ótica para a profissão. O PEP ganhou hegemonia no Serviço Social, sendo o orientador da formação e atuação profissional, mas ser hegemônico é diferente de ser homogêneo a toda a categoria.

[...] a elaboração e a afirmação (ou, se quiser, a construção e a consolidação) de um projeto profissional deve dar-se com a nítida consciência de que o pluralismo é um elemento factual da vida social e da própria profissão, que deve ser respeitado. Mas este respeito, que não deve ser confundido com uma tolerância liberal para com o ecletismo, não pode inibir a luta de ideias. Pelo contrário, o verdadeiro debate de ideias só pode ter como terreno adequado o pluralismo que, por sua vez, supõe, também 0 respeito às hegemonias legitimamente conquistadas (NETTO, 2006, p. 6). 


\section{temporalis}

Como vimos, esse processo vem sendo construído nas últimas décadas, requerendo organização política da categoria e disputas internas. Na contemporaneidade, o PEP é o projeto que norteia a profissão, fundamentado em elementos jurídicos normativos que explicitam o perfil de profissional que se quer formar e os elementos primordiais que devem perpassar a intervenção deste profissional.

O projeto ético-político do Serviço Social tem como valor central a liberdade, posicionando-se em prol da equidade, justiça social, universalização dos direitos, da democratização e socialização da riqueza produzida; comprometendo-se com o aperfeiçoamento intelectual constante, com uma formação acadêmica de qualidade, com uma intervenção sem discriminar e ser discriminado; contra todo e qualquer tipo de exploração e opressão, de classe social, etnia e orientação sexual (NETTO, 2006).

O PEP legitima um perfil profissional que deve sintonizar-se com seus componentes e pressupostos. De acordo com as diretrizes curriculares da ABEPSS, o perfil do bacharel em Serviço Social requer:

Profissional que atua nas expressões da questão social, formulando e implementando propostas para seu enfrentamento, por meio de políticas sociais públicas, empresariais, de organizações da sociedade civil e movimentos sociais. Profissional dotado de formação intelectual e cultural generalista crítica, competente em sua área de desempenho, com capacidade de inserção criativa e propositiva, no conjunto das relações sociais e no mercado de trabalho. Profissional comprometido com os valores e princípios norteadores do Código de Ética do Assistente Social (ABEPSS, 1997, p. 1).

Para isso, traça algumas competências e habilidades que a formação profissional deve garantir elementos que estejam em consonância com o PEP, como por exemplo: uma capacitação que envolva as três dimensões que constituem a profissão, teórico-metodológica, ético-política e técnico-operativas, abordando os fenômenos sociais na perspectiva da totalidade; a análise crítica da formação social brasileira e do desenvolvimento do capitalismo, possibilitando a compreensão do seu objeto de intervenção e análise, a questão social, que se gesta na relação contraditória entre capital x trabalho; além da necessária identificação das demandas que surgem no cotidiano da atuação profissional, traçando respostas qualificadas, não perdendo de vista os limites e possibilidades impostos ao Serviço Social (ABEPSS, 1997). 
A análise e a discussão dos documentos, leis e resoluções supracitados são indispensáveis na reflexão sobre a construção de um perfil profissional em sintonia com parâmetros e pressupostos radicalmente contrapostos ao perfil de outrora ancorado no tradicionalismo e conservadorismo.

Nossa argumentação retomou essa panorâmica exposição da história recente do Serviço Social para compreender sua configuração contemporânea, permitindo uma melhor análise do objeto desta pesquisa: o neoconservadorismo e sua relação com a formação profissional, especificamente na apreensão das/os discentes de graduação.

Como relatamos, essa contemporaneidade sinaliza uma tensão: polarização cada vez mais clara entre posicionamentos políticos em diferentes esferas, expressão multiforme das organizações e movimentos das lutas sociais mais diversas; e ataque reacionário aos direitos humanos. O processo de disputas, avanços e retrocessos que ocorre nas diferentes bandeiras de luta se firma e se expressa em distintos planos da vida social, como um furacão ideológico que reage e resiste nas expressões fragmentadas e capitalizadas das contradições sociais.

O avanço do que chamamos de neoconservadorismo é, sobretudo, uma reação. Tanto uma reação às intempéries da crise estrutural do capital nos planos da economia, da cultura e da política, como uma reação às diversas lutas e conquistas ocorridas no século XX, seja no mundo do trabalho, seja nas questões de gênero e diversidade sexual, juventude, raça e etnia, geração, entre outras.

É necessário apreender esse fenômeno em suas diversas demonstrações para construirmos uma real categorização da problemática e compreender como determinados complexos sociais e instituições, como as religiões, aparecem na reprodução dessas questões no cotidiano dos indivíduos e em outras esferas da sociabilidade, fazendo de sua peculiar natureza social um organismo sui generis dessas contradições.

Atentemos que a discussão não se finda apenas no moralismo em relação à sexualidade de mulheres e homens, suas orientações, suas identidades de gêneros e práticas afetivo-sexuais. Elas perpassam a disputa de hegemonia política e não somente em função de uma vontade meramente individual de um líder religioso, mas por 


\section{temporalis}

uma lógica intrínseca à natureza social das instituições em questão.

A sustentação do status quo finca suas bases na exploração da classe trabalhadora e em valores que reproduzem as diferentes opressões, em que se materializam desde a desigualdade social promulgada pela pobreza, miséria absoluta e desemprego em meio a outras questões, como a violência, tanto a nível estrutural, como cultural e social, atingindo sujeitos historicamente oprimidos, como mulheres, negros(as), homossexuais, entre outros.

Nesse contexto, exemplos não faltam dos choques ideológicos e políticos, a saber: movimentos de trabalhadores rurais em defesa da reforma agrária em atrito com os interesses do agronegócio e dos latifundiários; movimentos de estudantes que buscam minar a expansão do ensino superior precarizado e mercantilizado diante do lobby político das grandes instituições privadas de ensino que disputam essa fatia de mercado; grupos dos movimentos em defesa da diversidade sexual e movimento feminista em face aos mecanismos que espalham a visão moralista dos setores de extrema direita quanto às questões de gênero e homofobia.

O conservadorismo se estabelece maleável aos rearranjos necessários e à sua capacidade de manter sua força e direção consoante à conjuntura, seja para o reacionarismo, seja para o reformismo. Política, religião e preconceitos cotidianos aparecerão de maneiras, formas, intensidades distintas e desordenadas, mas frutos de um mesmo processo.

O quadro desafiador da contemporaneidade coloca o dilema iminente dos projetos individuais, que se formam, nessa conjuntura, ante um projeto profissional específico como o da profissão de Serviço Social e seu apontamento para um projeto societário contra-hegemônico. Como coloca Barroco (2011, p. 212-213) ao falar da tessitura entre as questões da profissão e a "barbárie" que se alastra no cotidiano de todos, percebe-se que:

A reatualização do conservadorismo é favorecida pela precarização das condições de trabalho e da formação profissional, pela falta de preparo técnico e teórico, pela fragilização de uma consciência crítica e política, o que pode motivar a busca de respostas pragmáticas e irracionalistas, a incorporação de técnicas aparentemente úteis em um contexto fragmentário e imediatista. A categoria não está imune aos processos de alienação, à influência 
do medo social, à violência, em suas formas subjetivas e objetivas. Isso coloca um imenso desafio ao projeto ético-político, na medida em que a sua viabilização não depende apenas da intencionalidade dos profissionais, tendo em vista as suas determinações objetivas, nem se resolve individualmente. Além disso, não podemos ignorar que o conservadorismo tem raízes históricas na profissão: para parcela da categoria, trata-se de uma opção política conscientemente adotada. Nesse sentido, a conjuntura pode favorecer a sua reatualização, sob novas roupagens e demandas.

Eis o desafio: a radicalidade da leitura concernente ao projeto ético-político do Serviço Social contrasta com as características da conjuntura atual, que marca um tempo de incertezas no mundo do trabalho e dimensionamentos peculiares no plano estatal. Criminalização dos movimentos sociais, precarização do trabalho, privatizações, desmantelamento das políticas sociais, ataque aos direitos humanos aparecem com formas e intensidades variantes, mas sempre acalorando o contexto das tensões que se concretizam nas disputas, nos limites e nos desafios da contemporaneidade.

As propagações do fundamentalismo religioso e da intolerância que avançam na contemporaneidade ganham contornos singulares para uma profissão que na atualidade afirma publicamente o combate aos preconceitos e às opressões, que defende o princípio de uma atuação laica e que busca consolidar, tanto a atuação profissional como a formação de futuros assistentes sociais, com base num arcabouço teórico crítico, radical e histórico.

Nesse sentido, as reflexões sobre os preconceitos e suas motivações na sociabilidade contemporânea não são, e nem devem ser, parte de uma análise com visão determinista, relacionando-a de forma direta e exclusiva com os aspectos econômicos e os processos de trabalho. Há que se perceber a ligação intrínseca e mediada desses elementos, para o entendimento amplo, crítico e profundo do fenômeno, entendendo como e quando as visões pré-concebidas são naturalizadas e reforçam opressões construídas historicamente, subjugando as diferenças em desigualdades sociais.

A formação de complexos sociais na dinâmica entre produção e reprodução social revela esse bojo valorativo em formas e planos distintos que se retroalimentam, onde as condições de desenvolvimento das alternativas dos indivíduos estão alicerçadas no chão da 


\section{temporalis}

história. Cada plano da vida social demonstra formas e contingências peculiares, permitindo diferentes maneiras de agir no campo da imediaticidade, que encobre a gama de mediações que edificam o cotidiano dos sujeitos. (LUKÁCS, 2013).

A propagação de preconceitos e desvalores acontecem de maneira complexa, tal qual é a necessidade de propagação de um ethos que abarque tantas mediações como na sociabilidade contemporânea. A esfera do cotidiano como um espaço com dimensão insuprível da sociabilidade é também e principalmente o espaço da imediaticidade e da superficialidade, onde a naturalização das questões aparece.

Se essas proposições permitem nos aproximar da essência das questões que envolvem o fundamentalismo religioso, ao evidenciar um atributo que estabelece a mitificação da ontologia do ser social e, a partir disso, reproduz a naturalização de tudo aquilo que foi construído socialmente sob determinações específicas, o entendimento do plano das disputas ideológicas e políticas nos coloca a possibilidade de desenvolver uma reflexão sobre essa linha tortuosa e fluida que se reproduz entre instituições, doutrinas e os dimensionamentos cotidianos de suas crenças.

Dessa forma, os referidos elementos nos oportuna entender: primeiro, o aspecto político, histórico e dinâmico das religiões, que se metamorfoseiam ao longo do tempo; segundo, num plano mais particular, apreender as aparentes incoerências individuais entre posicionamentos quanto a diferentes temas; terceiro, as crises individuais morais e éticas diante dos debates da ordem do dia, seja no plano da sociedade geral, seja no envolvimento com determinado projeto profissional, como no caso do Serviço Social.

Nesse sentido, perpassar as complexas mediações entre as determinações ontológicas e as expressões fenomênicas das opressões, evidenciando as contradições, os limites e as possibilidades no plano do cotidiano, é buscar evidenciar um processo dinâmico de reforço, construção e desconstrução de valores e desvalores que se chocam e dialogam com diversos da vida social.

Com base em todas essas considerações teóricas e históricas, revelamos que essas questões perpassam por uma série de mediações e determinações, que vão desde os condicionantes da universalidade das dimensões sociais até o constructo das personalidades dos 
indivíduos, permitindo, nesse processo, a apreensão das contradições sociais de modos e níveis diversos na reprodução, construção e reconstrução de valores, conceitos e preconceitos que se expressam no cotidiano dos sujeitos (LUKÁCS, 2013).

Ao imergir nas falas das/dos estudantes de Serviço Social - estes, envoltos numa conjuntura que, como sinalizamos, é reforçada por uma tensão social explícita e o desenvolvimento de diversas estratégias de reações de setores conservadores - o trato com a formação profissional se revela como um processo difícil, gerando crises subjetivas e diferentes formas de enfrentar as contradições de seus posicionamentos pessoais construídos ao longo de suas vidas com os posicionamentos desenvolvidos no âmbito universitário e na construção teórico-metodológica e ético-política da profissão.

\section{RELIGIÃO, VALORES E O PROJETO ÉTICO-POLÍTICO: AS PERCEPÇÕES DAS ESTUDANTES DE SERVIÇO SOCIAL}

Nos depoimentos das oito estudantes entrevistadas, encontramos indicadores múltiplos que resguardam tanto similitudes quanto particularidades em seus posicionamentos. Há níveis diferenciados de trazer sua religiosidade, bem como distintas formas de apreensão dos posicionamentos oriundos das respectivas instituições religiosas e suas incidências nas questões tratadas no processo de formação profissional.

O período em que estão no curso, as diferentes experiências pessoais no reforço ou na reconstrução dos seus valores, bem como a forma como foram interpeladas sobre essas questões na formação, também revelam percepções distintas do trato dado às contradições, que vão ficando cada vez mais claras para essas discentes.

A pluralidade de religiões e correntes internas também aparece nas falas e dão a elas contornos diferenciados. Cada estudante entrevistada aprofundou elementos esclarecendo as particularidades de cada experiência, com seus diferentes olhares cotidianos, carregados pela diversidade nas formas de pensar, de falar e de agir com relação aos temas provocados.

Nesse universo, encontramos religiosas protestantes que não gostam do termo evangélico, pois se consideram "evangelistas", como no caso da Estudante 07, discente do quinto semestre letivo, que coloca seus posicionamentos de modo sereno e se emociona ao 


\section{tempordils}

pensar que tantas outras pessoas "vivem sem o amor de Deus".

Essa diversidade também aparece em outro caso, como o da Estudante 03, também do quinto semestre, que se apresenta como "cristã tradicional" em detrimento do neopentecostalismo, garantindo suas convicções de modo firme, admitindo um choque inevitável com a formação profissional e até com o ambiente universitário mas, reafirmando sua "cosmovisão diferenciada", distinta de outras estudantes que, para ela, "se dizem cristãs, mas na formação assumem valores que são explicitamente contra o cristianismo".

Num outro exemplo, podemos destacar a Estudante 02: católica, que ainda no primeiro semestre revela suas dúvidas e expectativas, ao passo que expõe suas percepções da formação e da atuação profissional, desmistificando as imagens iniciais, reconstruindo seu entendimento, começando a perceber essas tensões no espaço de formação profissional e tendo uma percepção mais amena quanto aos seus valores religiosos e afirmação dos direitos.

Nessas múltiplas formas de perceber as questões, encontramos também o caso da Estudante 05: católica, do quinto semestre letivo, que chega a chorar relatando a crise subjetiva entre aquilo com que vem se deparando e se questionando, desde o início da formação em Serviço Social, e o espaço de seu grupo de oração na comunidade Shalom. Espaço esse até então responsável por mudanças consideradas fundamentais em sua vida, sendo local de acolhimento e desenvolvimento de qualidades individuais e que, agora, começava a ser também um lugar desconfortável e contraditório.

De forma distinta, a Estudante 01, evangélica, também atribui mudanças importantes em sua formação em Serviço Social. No entanto, destaca que elas são apenas em questões práticas, como no desenvolvimento da capacidade de falar em público, nos trabalhos em equipe e em outras questões que fiquem distantes dos valores religiosos, nos quais ela afirma ter conseguido estratégias para superar a crise subjetiva através de um "dualismo" de valores.

Podemos destacar ainda as particularidades presentes nas falas da Estudante 04, única entrevistada que se afirma da religião espírita, que discorre de modo distinto das demais sobre muitas questões, tratando os temas com desenvoltura, revelando um viés mais crítico e se aproximando das reflexões trazidas por sua formação, inclusive 
nas questões das quais discorda, como no exemplo da legalização do aborto.

Num quadro geral, o que mais se pode perceber nessas e nas outras entrevistas foi a recorrência da maioria das discentes com argumentações calcadas nos fundamentos religiosos para justificar as opiniões individuais, além da reprodução de muitos posicionamentos (e suas justificativas) trazidos pelas lideranças religiosas que estão em evidência na política formal quanto às questões da diversidade sexual e dos direitos reprodutivos da mulher.

Nas questões próprias da profissão, as falas evidenciaram percepções superficiais e distorcidas do projeto ético-político do Serviço Social, demonstraram como essas discentes buscam suas diferentes estratégias para superar as crises entre os valores individuais e os direcionamentos ético-políticos da profissão.

Nesse processo, as estudantes expuseram ainda questões não menos importantes, como as queixas de que alunas religiosas são tratadas com preconceito no curso de Serviço Social e que a forma como são abordados determinados temas afastam esse segmento antecipadamente por medo de um debate hostil.

As primeiras indagações que fizemos foi sobre o que motivou a escolha do curso de Serviço Social. As entrevistadas de diferentes semestres colocavam suas motivações, que se revelavam imprecisas quanto à identidade com a formação, devido ao pouco acúmulo sobre o que de fato era a atuação profissional e quais as atribuições do Serviço Social.

Quando eu iniciei o médio, a minha decisão foi medicina, e a minha vida toda foi medicina, mas a gente tem que ter a vocação para aquela profissão. Eu acredito que eu me dou muito com as ciências naturais, pra mim a pessoa fala ali e eu já aprendo, diferente das ciências sociais, que realmente a pessoa precisa refletir [...], mas eu não tinha vocação pra medicina, eu não ia aguentar passar minha vida toda trabalhando com gente doente. [...] então eu tentei direito, mas não, direito é muito sem graça, aí eu fiz o vestibular de psicologia, meu primeiro vestibular aqui e na Federal, só ficava na primeira fase. [...] aí eu tenho uma tia que é assistente social, e a minha mãe falava muito do trabalho dela, que achava bonito: "Filha, por que 


\section{temporalis}

você não tenta o serviço social? Tenta serviço social, você sabe falar, você é tão gentil, tenta". [...] tentei no final do ano de primeira pra serviço social, por influência da minha mãe e por essa tia. [...] eu não tinha essa noção de caridade, mas, pela disciplina que eu vi na grade curricular, e algumas coisas de psicologia... Aí foi por isso que eu entrei no serviço social, e eu acredito que hoje eu não estaria melhor em outra profissão do que no serviço social, realmente eu acho que eu tenho vocação pra ser assistente social [...] (Estudante 01).

Observamos que o motivo da escolha vai desde o fato de ser uma profissão aparentemente próxima daquelas da área da saúde, passando também pela identidade com os assuntos mais cobrados nas disciplinas específicas da área das ciências humanas na seleção do vestibular, além de noções superficiais, como o fato de ser uma profissão que "lida com pessoas".

A escolha do curso na maioria dos casos se deu de modo casual, dadas as circunstâncias adversas para lograr êxito nos cursos que eram prioridades de escolha. O pouco conhecimento sobre a formação e a atuação nesses casos intensifica a possibilidade de choques substanciais entre as expectativas dos discentes e a realidade da formação profissional

A compreensão superficial da profissão que perpassou o entendimento inicial das estudantes não advém de meras percepções individuais. Essa imagem do Serviço Social foi construída historicamente, sofrendo influência pelo modo com que a profissão foi criada e legitimada, como bem fundamenta as reflexões de Manrique de Castro (2011).

A reprodução estereotipada do que é o Serviço Social não é um dado exclusivo daqueles que buscam a formação, mas permanece presente em muitos espaços sócio-ocupacionais, na percepção de muitos gestores das políticas sociais, na imagem que alguns usuários constroem e até no entendimento de profissionais de outras áreas, fatores que geram inúmeros embates no campo de atuação para a afirmação das verdadeiras competências e atribuições da categoria. Quando questionamos sobre essa imagem da profissão, obtivemos respostas como:

Que o assistente social é a pessoa que ajuda. Eu lembro de uma moça que falou assim na sala: "Ai, eu escolhi porque 
eu gosto muito de ajudar, no Natal uma amiga de recuperação e eu lá em pleno dia de Natal ajudar na recuperação, então eu sou assim, você pode contar comigo toda hora". Eu me lembro muito dessa fala, porque hoje em dia é engraçado, né? [risos] Então eu acho que muitas pessoas entram assim, nessa visão de que eu vou poder ajudar as pessoas, perde um pouco a dimensão política, né? (Estudante 03).

O entendimento do Serviço Social como uma profissão que tem uma dimensão do cuidado, que está próxima à área da saúde ou que elenca questões das ciências humanas foram elementos que surgiram na maioria das falas, como destaca esta entrevistada sobre os cursos que eram prioridades para seus colegas e a relação que fizeram para escolher Serviço Social:

$$
\begin{aligned}
& \text { [...] acho que umas } 25 \text { ou } 30 \text { pessoas queriam fazer psi- } \\
& \text { cologia, a maioria, mas também eu acho que eu sou uma } \\
& \text { exceção por eu querer fazer fisioterapia, porque é uma } \\
& \text { área totalmente diferente de humanas, aí a maioria das } \\
& \text { pessoas ou faz serviço social ou faz psicologia [...], e che- } \\
& \text { ga achando que é parecido com psicologia, tipo: “Ah, lida } \\
& \text { com pessoas". Mas, quando a gente vai estudando, a gen- } \\
& \text { te vai percebendo que é uma coisa totalmente diferente } \\
& \text { de psicologia, é uma coisa à parte. Eu acho assim, se algu- } \\
& \text { ma pessoa hoje perguntar pra mim o que é serviço social, } \\
& \text { eu vou ficar olhando assim [...] (Estudante } 02 \text { ). }
\end{aligned}
$$

Essa percepção superficial quase sempre veio seguida de um forte impacto ao se deparar com o processo de formação profissional, as disciplinas, os conteúdos, os professores, os outros estudantes, um surpreendente conjunto de perspectivas que denunciavam contradições com muito daquilo que essas estudantes traziam como bagagem construída ao longo de suas vidas, nos seus espaços de socialização e convivência.

A reprodução do mero "cuidado", da "ajuda" e do "benefício" subjuga a dimensão do direito, da perspectiva de afirmação daquilo que foi conquistado coletivamente e está garantido por lei. Essa é uma identidade que foi construída em consonância com o processo histórico, atribuída de modo alienado nesse desenvolvimento e com a qual se busca romper na profissão.

O modo de compreender o Serviço Social nessa visão reflete 


\section{tempordlis}

a perseverança de um "reducionismo reacionário" historicamente construído, em que a representação social da categoria profissional retorna para esfera "do fazer com boa vontade" e "da vocação". Não por acaso, alguns depoimentos destacaram os conselhos de terceiros afirmando o "jeito de assistente social" de uma estudante ou ainda o "dom" de ajudar de outra.

Os questionamentos teórico-científicos próprios do ambiente acadêmico impactam de modo peculiar no entendimento dessas estudantes. Esses elementos se entremeiam às discussões em sala de aula junto a questões políticas, e as divergências passam a se colocar como notórias. Esse processo gera dúvidas e angústias nas estudantes, como podemos ver de acordo com as respostas dadas quando perguntamos se elas já haviam pensado em desistir do curso.

A Estudante 01 destaca as condições objetivas da formação como os principais elementos para sua desmotivação. Como já destacado, tanto as questões do mercado quanto a pressão social de vários planos e níveis, como a família e a escola, colocam desafios e inseguranças que se estabelecem de diferentes formas e direções.

Já as questões colocadas pelas outras duas estudantes expõem de fato as primeiras manifestações do choque de valores proporcionado pelo ambiente acadêmico, sobretudo no curso de Serviço Social e suas disciplinas curriculares. Nesse processo, não demora muito para que as questões dos valores religiosos se evidenciem e, com elas, as queixas e reinvindicações, tanto por uma suposta imposição do modo de pensar na (caberia: a ???) profissão, como também por compreenderem que o ambiente de formação profissional é desfavorável para os debates sob o prisma religioso.

Acho que algumas coisas, não sei se foram as pessoas que eu tive contato, mas todas são assim... As pessoas: “ah, o mundo tá errado", as pessoas são muito... Eu não posso dizer inconformada porque isso é bom, mas são muito de mal com a vida, entendeu? E tipo, eu não quero ser assim, tem muita gente, pessoas que eu tive contato: "ah, o governo é horrível, não sei o que é horrível, tudo é horrível". Eu sei que a maioria das coisas tão em crise mesmo, mas tem muitas coisas que ainda são boas que dá pra se aproveitar. Tem gente que quer mudar logo tudo, e às vezes não é assim (Estudante 02). 
O processo de socialização dessas discentes é uma construção que vem se desenvolvendo muito antes da chegada à universidade. Suas aspirações profissionais, seus valores individuais, a forma de se posicionar e o modo como enfrentam e enfrentarão as contradições extrapolam as questões de uma formação acadêmica em determinada profissão.

Uma linha tênue e complexa aparece nessa formação. Os debates e reflexões demonstram-se cada vez mais necessários, e a forma de fazê-los, mais desafiadora. Forma e conteúdo se colocam como provocações para o processo pedagógico da formação profissional que se processa em meio a condições desfavoráveis, visto que o ideário conservador se fundamenta em diversos planos da vida social, como aprofundamos com base nas reflexões lukacsianas e gramscianas na discussão sobre reprodução social.

As estudantes destacam que não são meras exceções, afirmando que muitos outros estudantes sentem esse incômodo com os temas, as formas de abordagens e as concepções:

$\mathrm{Na}$ aula de ética mesmo tem uma menina na minha sala que é muito religiosa, e às vezes a professora fala algumas coisas e todo mundo ri, só que são coisas. Que eu rio porque é engraçado, e ela começa a cochichar com outra, e às vezes eu escuto uma crítica e tal, e sem ela na verdade se permitir ao entendimento, porque não é preciso você deixar tudo por conta do serviço social, mas entender certas coisas que o serviço social te dá uma criticidade que nenhum outro curso te dá, e aí cabe a você permitir que esses questionamentos adentrem na sua vida de forma que você se torne... Porque hoje em dia eu não consigo olhar uma coisa e não questionar, é tanto que às vezes eu tenho brigas lá em casa porque meu pai fala as coisas e eu já vou logo questionando, mas às vezes sem necessidade, mas que já virou uma rotina minha, e eu acho que isso, não sei agora, mas provavelmente no futuro vai me influenciar muito, porque eu adquirindo essa cultura de questionamento é como se eu tivesse naquela ideia da dialética de que nada está posto, tudo está em movimento, então eu não posso aceitar que isso é assim sem questionar. Isso aqui vai mudar, e aí se eu parar de questionar aquilo eu também não vou questionar aqui. Eu adoro, eu amo o serviço social, principalmente essa ideia do questionamento e de respeito ao outro, de se reconhecer no outro (Estudante 05). 


\title{
tompordlis
}

Nas questões trazidas pelas estudantes, orbitam conceitos e entendimentos díspares do que é de fato uma atuação laica e qual o significado do pluralismo no debate profissional. A reinvindicação quanto à "liberdade de expressão" surge nessa e em muitas outras falas, sobretudo quando pautamos questões como a criminalização da homofobia, aborto ou laicidade do Estado.

\begin{abstract}
Eu acho que é mais em relação à questão mesmo dos cristãos, eu acho que é muito forte. Até na cadeira de ética, por exemplo, que a professora era bem incisiva mesmo em relação à religião, acho que não é nem em relação ao cristianismo, mas em relação à religião como um todo, mas principalmente em relação ao cristianismo. [...] Eu acho assim, de oprimidos as pessoas passam a ser opressores, porque são questões dos movimentos sociais, né, eu concordo, claro, com as minorias, que não são minorias, são maiorias, mas que de oprimidos eles podem passar a ser opressores desse ponto de vista, de não aceitar opinião diferente. Claro que eles não podem querer, eles têm que superar a questão dos opressores, as ideologias deles, enfim, mas não podem deixar de ouvi-las. Eu acho que essa questão da religião oprime, eu não nego isso, mas você não deixar de aceitar que existem pessoas que são religiosas e têm as religiões delas... (Estudante 7).
\end{abstract}

Entre eventuais razões que devem ser consideradas, revelando os possíveis equívocos no modo como os debates se constroem, ao supostamente trazerem tudo "pronto", sem permitir a apresentação, a reflexão e a tomada de posições no decorrer do diálogo, o que se explicita nas queixas é uma deformidade entre a liberdade de expressar sua crença, considerada como algo que não pode ser problematizada por ser a "sua" opinião, como destaca Barroco (2012, p. 68):

É comum o entendimento de que os pressupostos valorativos que servem de orientação para o julgamento das ações éticas podem variar de acordo com os valores pessoais dos indivíduos. Essa ideia concorre para uma relativização da ética e para uma visão que perpassa pelo pensamento social reproduzido pelo senso comum: a visão de que cada um tem a "sua" moral e a "sua" ética, desconectadas das suas determinações sociais, elou o entendimento de que elas decorrem da subjetividade dos indivíduos, não dispondo de determinações objetivas.

A questão se centra no entendimento de como, consoante 
uma compreensão da esfera do direito, do desenvolvimento da atuação profissional de uma categoria que corrobora sua dimensão técnico-operativa em fundamentos teórico-metodológicos e ético-políticos, posto ser uma profissão atrelada às ciências sociais aplicadas, se exige que o conjunto de suas diretrizes, atribuições e competências esteja circunscrito em um viés objetivo e coletivo.

Embora não elimine os valores religiosos da vida dos sujeitos, já que esse é um direito que deve ser garantido, essa dimensão coloca o debate em uma esfera distinta dessa dimensão espiritual-religiosa:

O fato de a prática obedecer a ordenamentos legais e o ensino estar fundamentado em teorias, como o marxismo e a psicanálise, não impede que conteúdos valóricos, oriundos da raiz social destes profissionais, ou de sua predominância de gênero ou ainda de suas marcas religiosas, não estejam a ela agregados, quando a maioria dos profissionais detém tal perfil (SIMÕES, 2005, p.15-16).

Assim, nenhuma entidade da profissão coíbe que cada estudante ou profissional possa ter sua crença individual. No entanto, as discussões sobre os direcionamentos profissionais devem ser tomadas por argumentos que se estabeleçam na esfera circunscrita à profissão e ao conjunto de entidades e sujeitos que constroem o projeto profissional.

Isso revela que a liberdade individual de crença é e deve ser garantida, mas nenhuma crença religiosa deve pautar a atuação de indivíduos ou grupos no exercício da profissão. Na disputa por essas concepções, a busca por direitos e a manutenção de privilégios de determinados grupos adensam um forte antagonismo. Para Barroco (2012, p. 74):

O preconceito se transforma em moralismo quando julgamos o comportamento dos outros segundo critérios morais em uma situação que não é para ser julgada moralmente. São atitudes discriminatórias que negam serviços ou desrespeitam usuários, em função de preconceitos, respaldando-se em ideias conservadoras da sociedade; logo, contam com uma base social de apoio para se manifestar, como dissemos as ações implicam responsabilidades, pois - independente da intencionalidade - acarretam consequências.

O pluralismo, como Netto (2006) bem destaca, trata-se de uma 


\section{tempordlis}

abertura para a discussão, para a problematização, para a disputa de concepções com argumentos sólidos e fundamentados. Esse diálogo não sucumbe à possibilidade de uma hegemonia política e teórica construída nesse processo, nem a coloca como um conjunto uníssono e estático.

É necessário refletir sobre as estratégias didático-pedagógicas da formação profissional, pensar como e com que meios se pode garantir a melhor maneira de elencar temas e direções para a efetivação dos objetivos que o curso estabelece, visto que, no processo pedagógico, a construção, desconstrução e reconstrução de concepções não se estabelecem de modo rápido e direto.

Garantir um processo amplo e democrático no espaço de formação profissional e propiciar ocasiões em que os debates ocorram de modo sincero é um passo primordial para buscar a problematização dessas contradições. O processo de ensino-aprendizagem deve afirmar as questões teóricas e ético-políticas da profissão, entendendo a especificidade do espaço educativo e formativo que abarca sujeitos com diferentes percepções e experiências individuais dialogando com aquilo que lhes é apresentado.

O modo como cada estudante percebe as polêmicas religiosas nas discussões é um componente substancial. A Estudante 04, adepta do espiritismo, faz uma leitura crítica dos debates, destaca os problemas trazidos pelas argumentações de cunho fundamentalista religioso como uma dificuldade para a afirmação dos direitos.

Entre aquelas estudantes que estão ligadas às religiões e grupos fundamentalistas cristãos, o embate entre as questões religiosas trazidas pelos indivíduos se expressa também em níveis distintos. No entanto, entre as certezas reproduzidas por suas doutrinas, todos os depoimentos trazem, em alguma medida, uma carga de angústia e questionamentos.

O debate manifesto no âmbito de diferentes planos, conhecimentos e naturezas sociais que se expressa nessa contradição entre os valores religiosos no espaço de formação profissional também não ocorre de modo tranquilo na subjetividade dessas discentes. Não se trata apenas dos conhecimentos teóricos, nem dos debates em sala de aula, mas de um ambiente diferenciado, da possibilidade de socialização com indivíduos e grupos distintos do que até então era habi- 
tual.

A universidade é um lócus de novas experiências, novas amizades, de novos questionamentos cotidianos. Os dilemas teóricos e políticos passam a ser também dilemas emocionais, enfrentados ou reforçados por meio dos recursos entremeados na rede de relações dessas estudantes. O grupo de oração, a família, as colegas estudantes, tudo e todos podem se tornar um espaço ou ferramenta para expressar diferenças e antagonismos, reforçando valores ou possibilitando nossos questionamentos.

\section{CONSIDERAÇÕES FINAIS}

A importância da questão do conservadorismo e do fundamentalismo religioso não se define nem como início, nem como fim dos elementos essenciais da reprodução do binômio exploração/opressão, mas se caracterizam como uma importante e fundamental mediação do complexo de complexos que se estabelecem na sociabilidade contemporânea, marcada por uma teia de fenômenos distintos, mas que se intercruzam na exacerbação das contradições basilares da estrutura social.

Quando cada vez mais pessoas nos movimentos sociais, nos debates políticos e também nas universidades buscam os argumentos religiosos para reforçar seus preconceitos, é fundamental aprofundar esse entendimento das expressões do neoconservadorismo religioso, com exemplo nos sujeitos que buscam a formação em Serviço Social e se deparam com as atuais condições e defesas do projeto ético-político.

A realização deste estudo possibilitou compreender a complexidade que envolve o diálogo entre o conteúdo proposto na formação profissional do Serviço Social e os valores religiosos trazidos pelas estudantes. Esse embate denota conflitos individuais, que extrapolam a dimensão subjetiva e refletem em posicionamentos que adentram a esfera da atuação profissional.

Diante do que discutimos na pesquisa e de modo panorâmico neste texto, podemos reafirmar a complexidade desse fenômeno e a urgência de aprofundarmos as reflexões. Explicitar tal problemática denota que esta síntese traz mais considerações do que conclusões, já que a dinâmica em que se manifesta o fundamentalismo religioso vem pautada em uma teia densa de questões e relações díspares que 


\section{tempordlis}

se retroalimentam em constante transformação. Essa lógica avança fortalecendo privilégios historicamente construídos na sociedade brasileira, numa direção apropriada pelos moldes da conjuntura contemporânea da sociedade burguesa, capaz de tornar funcional ao seu modo de produção e reprodução as mais arcaicas formas de embasamento ideológico das opressões.

Os dados, os relatos e as reflexões teóricas apresentadas neste trabalho só explicitam que esse tema, o campo de pesquisa, os sujeitos entrevistados e seus depoimentos ainda preservam muitos elementos para análise do fenômeno. A dinâmica do real, a riqueza de informações e de experiências reveladas neste estudo, fornecem a certeza que há ainda um longo percurso por via das férteis mediações e determinações que formam essa complexa, ampla e instigante temática.

A maneira como os diferentes sujeitos dialogam com aquilo que orbita sua socialização resguarda um espaço de autonomia na construção e no modo de se relacionar com os demais seres, com as instituições e com a inserção nos distintos complexos sociais, evidenciando uma perene construção, desconstrução e manutenção de valores, costumes e juízos individuais e coletivos.

As dificuldades relatadas pelas discentes são também expressões desses desafios da formação profissional. O difícil modo de desenvolver pedagogicamente os debates aparece não pela ineficácia ou amortecimento dos pilares que constituem o arcabouço teóricometodológico e a direção ético-política da profissão. Ao contrário, a capacidade de percebermos esses choques nos relatos e dados aqui expostos é a expressão da vitalidade do compromisso crítico na formação profissional.

A conjuntura atual profere seus desafios, explicitando também a necessidade de fortalecer estratégias que vem atravessando as últimas décadas para a continuidade desse processo de combate e ruptura com o conservadorismo. Este estudo denota que a expressão do neoconservadorismo sob o véu do fundamentalismo religioso, explícito nos debates públicos, na política formal e na luta por direitos e pela concepção deles, resguarda sua base e manifestação cotidiana, capilarizada em espaços diversos, evidenciadas nos posicionamentos de tantos indivíduos que reproduzem pensamentos e atitudes de reforço de preconceitos e opressões. 
Para a profissão de Serviço Social, fica claro também que o ranço histórico de conservadorismo que se construiu, imbricado com os fundamentos religiosos, persiste na imagem social estereotipada da profissão, mas também sob as declarações e entendimento de muitos sujeitos que buscam a formação profissional.

Os desafios postos para a profissão e seu direcionamento ético-político, em particular em seu processo de formação profissional no âmbito da academia, são provocações elementares para essa práxis que surge e se estabelece no meio dos antagonismos de classes inerentes a essa sociabilidade, mas ainda se tornam manifestos em sua total condição por esse caráter diferenciado que é proposto para desvendar, intervir e transformar as expressões dessas contradições.

O combate ao conservadorismo segue uma trajetória que atravessa as últimas décadas e se depara com velhos e novos modos de espraiamento e estabelecimento de suas manifestações. O arcabouço teórico-metodológico e a direção ético-política são o pano de fundo de fortalecimento coletivo da profissão e de sua formação profissional crítica e com sentido emancipatório.

\section{REFERÊNCIAS}

ABEPSS. Associação Brasileira de Ensino e Pesquisa em Serviço Social. Diretrizes curriculares do curso de Serviço Social. Cadernos ABESS, São Paulo, n. 7, 1997.

. Diretrizes gerais para o curso de Serviço Social. 2012. Disponível em: <www.abepss.org.br>. Acesso em: 2 ago. 2013.

BARROCO, M. L. S. Ética e Serviço Social: fundamentos ontológicos. São Paulo: Cortez, 2007.

- Barbárie e neoconservadorismo: os desafios do projeto ético-político. Serviço Social \& Sociedade. São Paulo, n. 106, p. 205-218, abr./jun. 2011.

; TERRA, Sylvia Helena. (Org.). Código de ética do/a assistente social comentado. São Paulo: Cortez, 2012.

. Fundamentos éticos do Serviço Social. Curso de especialização à distância. Serviço Social: Direitos sociais e competências profissionais. Brasília: ABEPSS, 2009. 


\section{tempordlis}

BRAZ, Marcelo. A hegemonia em xeque: projeto ético-político do Serviço Social e seus elementos constitutivos. Revista Inscrita, Rio de Janeiro, ano VII, n. 10, p. 4-10, nov. 2007.

. TEIXEIRA, J. B. O projeto ético-político do Serviço Social. 2006. Disponível em: <http://pt.scribd.com/doc/92179247/4-O-Projeto-Etico-politico-Do-Servico-Social>. Acesso em: 2 mar. 2013.

BRASIL. Código de ética do/a assistente social. Lei 8.662/93 de regulamentação da profissão. Brasília, DF: Conselho Federal de Serviço Social, 2012.

CASTRO, M. M. História do Serviço Social na América Latina. São Paulo: Cortez, 2011.

ESCORSIM NETTO, L. O conservadorismo clássico: elementos de caracterização e crítica. São Paulo: Cortez, 2011.

IAMAMOTO, M. V. Renovação e conservadorismo no Serviço Social: ensaios críticos. São Paulo: Cortez, 1992.

LÖWY, M. A guerra dos deuses: religião e política na América Latina. Petrópolis: Vozes, 2000.

LUKÁCS, G. Prolegômenos para uma ontologia do ser social: questões de princípios para uma ontologia hoje tornada possível. São Paulo: Boitempo, 2010.

. Para uma ontologia do ser social I. São Paulo: Boitempo, 2013.

PAULO NETTO, J. Capitalismo monopolista e Serviço Social. São Paulo, Cortez, 2011a.

. Ditadura e Serviço Social. São Paulo: Cortez, 2011b.

. A construção do projeto ético-político do serviço social. In: $\overline{M O T A}, A$. E. et al. (Org.). Serviço Social e saúde: formação e trabalho profissional. São Paulo: Cortez, 2006.

SANTOS, J. S. Neoconservadorismo pós-moderno e Serviço Social brasileiro. São Paulo: Cortez, 2007. (Questões da nossa época, v. 132).

SIMÕES, P. Assistentes Sociais e religião. São Paulo: Cortez, 2005. 